\title{
Higher spatial than seasonal variation in floodplain soil eukaryotic microbial communities
}

\author{
Bertrand Fournier $^{\mathrm{a}, \mathrm{b}, 1,{ }^{*}, \text { Emanuela Samaritani }}{ }^{\mathrm{c}, 1}$, Beat Frey ${ }^{\mathrm{d}}$, Christophe V.W. Seppey $^{\mathrm{e}}$, \\ Enrique Lara $^{\mathrm{f}}$, Thierry J. Heger ${ }^{\mathrm{a}, 2}$, Edward A.D. Mitchell ${ }^{\mathrm{c}, \mathrm{g}, 2}$ \\ ${ }^{a}$ Soil Science and Environment Group, Changins, University of Applied Sciences and Arts Western Switzerland, Route de Duillier 50, 1260, Nyon, Switzerland \\ ${ }^{\mathrm{b}}$ University of Potsdam, Institute of Environmental Science and Geography, Potsdam, Germany \\ ${ }^{\mathrm{c}}$ Laboratory of Soil Biodiversity, University of Neuchâtel, Rue Emile Argand 11, 2000, Neuchâtel, Switzerland \\ ${ }^{\mathrm{d}}$ Swiss Federal Institute for Forest, Snow, and Landscape Research WSL, Zürcherstrasse 111, 8903, Birmensdorf, Switzerland \\ ${ }^{\mathrm{e}}$ Microorganisms and Plants Group, Department of Arctic and Marine Biology, Faculty of Biosciences, Fisheries and Economics, University of Troms $\phi$, Framstredet 39, \\ 9037, Troms $\phi$, Norway \\ ${ }^{\mathrm{f}}$ Real Jardín Botánico, CSIC, Plaza de Murillo 2, ES 28014, Madrid, Spain \\ ${ }^{g}$ Jardin Botanique de Neuchâtel, Chemin du Pertuis-du-Sault 58, 2000, Neuchâtel, Switzerland
}

\section{A R T I C L E I N F O}

\section{Keywords:}

Soil protist

Beta diversity

Spatiotemporal dynamics

Soil physico-chemical conditions

Soil ecosystem functions

Riparian ecosystem

\begin{abstract}
A B S T R A C T
Beta diversity is a key component of biodiversity with implications ranging from species dynamics to ecosystem functioning. However, $\beta$-diversity and its drivers have received little attention, especially for micro-eukaryotes which play key roles in soil functioning. We studied the diversity of soil micro-eukaryotes in a Swiss lowland floodplain using high-throughput Illumina sequencing of soil DNA. We determined the temporal vs. spatial patterns of soil micro-eukaryotic $\alpha$ - and $\beta$-diversity in six contrasted habitats sampled over one year. We identified the drivers of these patterns among soil conditions and functions and identified indicator taxa of habitats in each season. We found higher spatial than temporal variability and a strong space-time interaction in soil microeukaryotic diversity patterns as well as in their edaphic drivers, which contrasts with previous observation of bacterial diversity patterns. Our results show that, although soil micro-eukaryotic diversity indeed varies seasonally, it is correlated most strongly with edaphic variables and vegetation but the strength of correlations with individual drivers varied seasonally. Microbial diversity patterns and their drivers can thus differ quite substantially among seasons and taxa. Despite the dominance of spatial patterns, the temporal component of microbial diversity should not be ignored to accurately estimate the diversity and the complexity of soil microbial community assembly processes. Given the importance of soil microbial diversity for ecosystem functioning such knowledge is relevant for land management.
\end{abstract}

\section{Introduction}

Soil microbial eukaryotes (here including protists and fungi, but excluding micro-metazoans) are highly diverse and play central roles in soil food webs (Geisen, 2016). They are thus key actors of biogeochemical cycling: they influence nutrient cycling and energy fluxes in soils via the microbial loop (Bonkowski, 2004), thus contributing to soil fertility (Barrios, 2007; de Vries et al., 2013). However, there are still significant gaps in basic knowledge of the diversity and ecology of soil microbial eukaryotic communities. Notably, analyses of seasonal dynamics of soil microbial eukaryotic communities are rare and limited to a relatively small range of ecosystem types.

With the development of high-throughput multi-taxa identification using environmental DNA, hereafter eDNA metabarcoding (Taberlet et al., 2012), more efficient and complete characterization of microbial eukaryotic diversity is possible. Indeed, macroecological patterns such as the latitudinal biodiversity gradient, which are well documented in macro-organisms, were also observed in several major groups of soil fungi, but not in ectomycorrhizal fungi (Tedersoo et al., 2014). Similarly, morphological and molecular studies showed an increase of

\footnotetext{
* Corresponding author. University of Potsdam, Institute of Environmental Science and Geography, Potsdam, Germany.

E-mail address: bfourni@gmail.com (B. Fournier).

1 Joint 1st authors.

2 Joint last authors.
} 
diversity toward the equator for euglyphid testate amoebae (Lara et al., 2016) or towards mid-latitudes where the water-energy balance is maximal for all testate amoebae (Fernández et al., 2016). There is compelling evidence that at least some micro-eukaryote taxa are not globally distributed, and that the composition of communities diverges considerably across large geographic distances (Foissner, 2006; Heger et al., 2013). Furthermore, environmental distance-decay similarity in diatom communities were shown to be comparable to that observed in macro-organisms (Astorga et al., 2012). Morphological- and DNA-based fine-scale analyses of the spatial variations of soil microbial eukaryotic communities are scarce (Mitchell et al., 2000; Acosta-Mercado and Lynn, 2002). But, Fiore-Donno et al. (2019) have shown, using a metabarcoding approach, that the spatiotemporal heterogeneity of edaphic factors can drive the changes in microbial eukaryotic community compositions highlighting the importance of deterministic niche-based processes. Despite the methodological progress, studies investigating the patterns of diversity distribution and biogeography of microbial eukaryotes are less numerous than for bacteria and often do not consider temporal changes. The few studies that have investigated the temporal changes of soil microbial eukaryotic communities have revealed a marked seasonality (Lamentowicz et al., 2013; Fiore-Donno et al., 2019; Levy-Booth et al., 2019; Zhao et al., 2019). A better characterization of the relative importance of seasonal as compared to spatial variability in soil microbial eukaryotic communities can improve our understanding of community assembly processes, and is necessary to clarify the patterns and drivers of diversity and biogeography of soil microbial communities.

Beta diversity measures the differences in community composition among sites within a region of interest (Whittaker, 1960). Many different definitions and metrics of beta diversity exist (Tuomisto, 2010). In its additive form (i.e. $\beta=\gamma-\alpha$ ), beta diversity can be defined as the amount by which the species richness of the entire (regional) dataset exceeds that of a single sampling unit of mean species richness (Tuomisto, 2010). This approach allows quantifying the relative importance of alpha and beta diversity for total gamma diversity. While it is widely used for the study of macro-organisms (Wagner et al., 2000; Gering et al., 2003; Tylianakis et al., 2005; Schmidt et al., 2017), such an approach has, to our knowledge, never been used to assess the variability of soil microbial eukaryotic communities.

We focus on the spatiotemporal variability of soil microbial eukaryotes in riparian soils. Floodplains, at the interface between the riverbed and the surrounding upland terrestrial ecosystems (Sedell et al., 1989), are among the most diverse environments on earth. They are characterized by sharp environmental gradients and are strongly influenced by the seasonal dynamics of the river. Riparian soils contain a high diversity of eukaryotic microorganisms (Foissner et al., 2007; Baldwin et al., 2013), that is very heterogeneously distributed among the various floodplain habitats (Binkley et al., 1997). Previous studies about the seasonal variations of soil microbial eukaryotic communities were conducted in habitats with relatively low spatial variability in environmental conditions such as temperate rainforests (Levy-Booth et al., 2019), agricultural soils (Zhao et al., 2019), and grasslands (Fiore-Donno et al., 2019) which might lead to a biased view of the relative importance of spatial and seasonal beta diversity. In the few cases where protist communities of temporarily flooded systems were investigated, and where the temporal dimension was included, marked seasonal patterns were observed (Simon et al., 2015; Sisson et al., 2018). A better knowledge of the patterns and drivers of soil micro-eukaryotic diversity in a broader range of ecosystems types is needed to improve our understanding of the structure and functions of soil ecosystems in general. Dynamic systems such as floodplains characterized by irregular perturbations have to this date not been studied for soil micro-eukaryotes. And, virtually nothing is known about the seasonal variability of floodplain soil microbial eukaryotic communities despite strong and well-known seasonal changes in climate and flood dynamics. Riparian soils are thus ideal model ecosystems to investigate the spatiotemporal variability of soil microbial eukaryotic communities (Sedell et al., 1989).

We present the results of a field survey of soil microbial eukaryotic communities in a Swiss lowland floodplain. The survey was conducted in six contrasted characteristic floodplain habitats with four seasonally replicated sampling campaigns. The purpose of this study was to examine the richness and turnover (beta diversity) of microbial eukaryote taxa in relation to the spatial, temporal, and edaphic characteristics of the selected habitats. As our focus is on taxa richness and turnover to quantify the spatiotemporal changes of soil microeukaryotic assemblages, we decomposed the total diversity into spatial and temporal components. Finally, we related these indices to measured variables reflecting soil conditions and functions. We expected a stronger contribution of habitats to total beta diversity because of the marked differences in soil conditions and functions (Samaritani et al., 2011), vegetation type (Fournier et al., 2013), and soil organism groups (Fournier et al. 2012a, 2012b, 2015) at the study site. However, we expected the important seasonal changes in soil and climate to induce significant temporal changes of soil microbial eukaryotic communities. Our results confirmed these expectations by showing that beta diversity (spatial and temporal) contributes to a greater extent to total gamma diversity than local alpha diversity. And, although important, seasonal changes in soil microbial eukaryotic communities were less marked than spatial ones. These results highlight the importance of considering both the spatial and temporal changes for understanding soil microbial eukaryotic diversity and functions.

\section{Experimental procedure}

\subsection{Study site}

The study was conducted in a restored section of the River Thur in north-western Switzerland. River Thur flows through the Swiss Plateau from Mount Säntis to the Rhine. Its regime is similar to that of alpine rivers, with peak flow generally occurring in spring after snowmelt and in summer and fall after large storms. The study site is a $1.5 \mathrm{~km}$ long recently restored section of the river located in a peri-urban/agricultural region of Switzerland (long-term maximum, mean, and minimum flow rates are 1130, 50, and $2 \mathrm{~m}^{3} \mathrm{~s}^{-1}$, respectively; 1904-2005: http://www. hydrodaten.admin.ch/en/index.html). More information about the study site can be found in Schirmer et al. (2014) and Woolsey et al. (2007).

\subsection{Sampling design}

Six habitats were distinguished based on flood dynamics (assessed using topographic conditions: distance to the river and elevation) as well as soil and vegetation characteristics (Gravel, Grass, Willow bush, Mixed forest, Willow forest, and Pasture; Fig. S1). Gravel is characterized by frequent floods (average $=24$ floods $\mathrm{y}^{-1}$ ), patches of poorly developed soils (Calcaric Regosols), and pioneer vegetation. Grass is characterized by frequent floods (average $=17$ floods $\mathrm{y}^{-1}$ ), more developed soils (Calcaric Regosols) with a high spatial and temporal heterogeneity (Samaritani et al., 2011), and dense vegetation dominated by tall herbs (Phalaris arundinacea). Willow Bush experiences on average three floods per year and has soils of average depth (Calcaric Fluvisols) where willow bushes (mostly Salix viminalis) were planted. Mixed Forest is subjected to limited influence of flooding $\left(0.2\right.$ flood $\left.\mathrm{y}^{-1}\right)$, has deep soils (Calcaric Fluvisols), and is dominated by mixed deciduous tree species (Acer pseudoplatanus, Fraxinus excelsior). Willow Forest occurs at a similar distance to the river than Mixed Forest, but at a slightly lower elevation. It experiences on average 0.5 flood per year, has deep soils with more hydromorphic features than Mixed forest (Calcaric Gleyic Fluvisols), and the vegetation is dominated by old willows (Salix alba). Finally, Pasture lies outside the restored section of the river and is still protected from floods by levees (number of floods per year $<0.2$ ), has the most 
developed soils (Calcaric Fluvisols), and harbors the typical vegetation of a grassland. The number of floods per year per habitat was calculated in Fournier et al. (2015). The soil taxonomy was assessed by Fournier et al. (2013) according to the World reference base for soil resources (IUSS Working Group, 2006). Four plots were sampled in each habitat and each plot was sampled four times (spring = April 09, 2008; summer = July 08, 2008; autumn = October 08, 2008; and winter = January 09, 2009; $\mathrm{N}=24 * 4=96$ samples). This design aimed at capturing a maximum of the fine-scale spatial and temporal heterogeneity within the study site without a priori knowledge of environmental conditions.

\subsection{Soil physico-chemical conditions}

Soil physico-chemical variables were presented by Samaritani et al. (2011). Soil texture (sand; silt; clay) was measured on dried samples using the pipette method (Gee and Bauder, 1986). The percentage of total organic carbon (TOC) of dried, homogenized soils was measured using a TOC analyzer (Shimadzu, Tokyo, Japan) after $\mathrm{HCl}(10 \%)$ acid digestion to remove carbohydrates. Total carbon and nitrogen contents were measured using an automatic element analyzer (Shimadzu, Tokyo, Japan). The Olsen P method was used as a proxy of available P (Kuo, 1996). Soil temperature (T) at $5 \mathrm{~cm}$ depth was continuously measured during this study in each plot at 30 min resolution with TidBit v2 temperature loggers (Bourne, MA, USA). Soil Moisture (SM) was estimated at each sampling time by measuring the weight loss upon drying $20 \mathrm{~g}$ of fresh soil at $105{ }^{\circ} \mathrm{C}$ for $24 \mathrm{~h}$. See Samaritani et al. (2011) for further details about the measurements of soil conditions.

\subsection{Ecosystem functioning proxies}

Four variables indicative of soil functioning were selected and measured in each plot and season: basal respiration, microbial biomass (carbon and nitrogen), and enzymatic activity. These variables are ecosystem functioning proxies that can be linked to ecosystem services such as decomposition, nutrient cycling and carbon storage. Basal respiration (BR) was measured in a closed soil-chamber system connected to a Li-8100 infrared gas analyzer (LI-COR Inc., Lincoln, NE, USA) (Samaritani et al., 2017). The gas flow and the $\mathrm{CO}_{2}$ concentration were recorded and the $\mathrm{BR}$ was calculated according to Rieder et al. (2013). Fluxes are reported as $\mathrm{mmol} \mathrm{CO}_{2} \mathrm{~h}^{-1} \mathrm{~g}^{-1}$ soil dry weight. Microbial biomass Carbon (MC) and Nitrogen (MN) were determined by chloroform fumigation-extraction (Vance et al., 1987; Frey et al., 2006; Samaritani et al., 2011). MC and MN data were expressed in $\mathrm{mg} \mathrm{kg}^{-1}$ soil dry weight. Enzymatic activity (EA) was estimated by fluorescein diacetate analysis (see Samaritani et al., 2017 for more information). Fluorescein diacetate (FDA) is hydrolysed by proteases, lipases and esterases and can therefore be used to determine the microbial activity (Söderström, 1977; Schnürer and Rosswall, 1982; Adam and Duncan, 2001). The formation of a yellow color was assessed at $490 \mathrm{~nm}$ by spectrophotometer. The intensity of the resulting yellow color is indicative of the amount of enzymatic cleavage of the FDA molecule (colorless) and the overall enzymatic activity in the sample. The results were expressed in $\mathrm{mg}$ of degraded FDA $\mathrm{h}^{-1} \mathrm{~g}^{-1}$ soil dry weight.

\subsection{DNA extraction}

We used aliquot of soil DNA from the study of Samaritani et al. (2017). Briefly, a $0.5 \mathrm{~g}$ subsample of fresh soil and $0.75 \mathrm{~g}$ glass beads ( $0.1 \mathrm{~mm}$ diameter) were suspended in $1 \mathrm{ml}$ extraction buffer $(0.2 \mathrm{M}$ $\mathrm{Na}_{3} \mathrm{PO}_{4}$ [pH 8], $0.1 \mathrm{M} \mathrm{NaCl}, 50 \mathrm{mM}$ EDTA, 0.2\% CTAB). The DNA was purified by chloroform extraction with $2 \mathrm{ml}$ chloroform. The DNA was precipitated by the addition of $3 \mathrm{ml}$ of precipitation solution (20\% PEG $6000,2.5 \mathrm{M} \mathrm{NaCl}$ ). The supernatant was removed and the samples were air dried for $20 \mathrm{~min}$, and re-suspended in AE buffer (10 mM TrisCl, 0.5 mM EDTA, pH9; Qiagen, Hilden, Germany) at $1 \mathrm{ml}$ AE per $g$ of extracted soil (dry weight equivalent). The extracted DNA was examined by electrophoresis on agarose gels ( $1 \% \mathrm{w} / \mathrm{v}$ in Tris-Borate-EDTA buffer), quantified using PicoGreen and stored at $-20^{\circ} \mathrm{C}$.

\section{6. $18 S$ rRNA amplification and illumina sequencing}

The microbial eukaryotic communities were investigated using highthroughput Illumina sequencing. The V9 SSU rRNA hypervariable region was amplified with the general eukaryotic primer pair 1380f/1510r (Amaral-Zettler et al., 2009). The forward primers were tagged with 96 different 9 nucleotides long keys. In a total volume of $30 \mu \mathrm{l}$ we added 1 ng of DNA, $6 \mu \mathrm{l}$ of 10xPCR buffer, $0.6 \mu \mathrm{l}$ of each primer, $0.6 \mu \mathrm{l}$ of each dNTP $400 \mu \mathrm{M}$ (Promega), and $0.2 \mu \mathrm{l}$ of $0.05 \mathrm{U} \mu \mathrm{l}-1$ Hotstar Taq-polymerase (Qiagen). PCR amplification was performed with a PTC-100 thermocycler (MJ Research, Waltham, MA, USA). Each PCR reaction was repeated in triplicates and a negative control was run for each differently tagged primer combination was run. Amplification conditions followed Amaral-Zettler et al. (2009) protocol: 3 min denaturation at $94{ }^{\circ} \mathrm{C}$, followed by 30 cycles of $30 \mathrm{~s}$ at $94{ }^{\circ} \mathrm{C}, 60 \mathrm{~s}$ at $57^{\circ} \mathrm{C}$, and $90 \mathrm{~s}$ at $72{ }^{\circ} \mathrm{C}$ and final extension at $72{ }^{\circ} \mathrm{C}$ for $10 \mathrm{~min}$.

The three PCR products from each sample were combined and purified through Zymo columns. Then, approximately $4 \mathrm{ng}$ of amplicons for each sample were pooled together. Amplicons were quantified by fluorometry with the QuBit HS dsDNA kit (Life Technologies, Carlsbad, CA). A DNA library was prepared for Illumina sequencing following New England Biolabs's kit NEBNext DNA Sample Prep Master Mix Set 1. The $100 \mathrm{bp}$ paired-end sequencing run was performed with the Illumina HiSeq2000 platform at the Genomics Core Facility of Brown University (Providence, USA). The sequencing provided a total of 221'625'392 barcoded reads. The amplicon data are available on EMBL European Nucleotide Archive under project number: PRJEB35438 (ERP118478).

\subsection{Sequence data processing and taxonomic assignment}

The absence of sequencing primers in the dataset was verified using cutadapt (Martin, 2011). The analysis of the reads was then done with the DADA2 package (version 1.12) in $R$ version 3.5.0 ( $\mathrm{R}$ Development Core Team, 2018). The DADA2 pipeline includes the following steps: filtering, dereplication, sample inference, chimera identification, and merging of paired-end reads. DADA2 infers exact amplicon sequence variants (ASVs) from sequencing data (Callahan et al., 2016). The ASVs were then taxonomically assigned with QIIME2 (Bolyen et al., 2018) using a pre-trained Naive Bayes classifiers (Silva Ref NR 99, release 132) (Quast et al., 2012). All ASVs which were not assigned to Nucletmycea or a protist group were removed from the dataset. After this all ASVs representing less than $1 \%$ of the average sampling depth were removed (from 14900 ASVs to 13909 ASVs). This was done to remove potential technical artifacts.

\subsection{Spatial and temporal changes of ASV richness}

The analyses were first focused on the changes in ASV richness among habitats and seasons. The importance of seasons, habitat types, and their interaction as potential drivers of changes in soil microeukaryotic ASV richness was assessed. A linear model using ASV richness as a response and habitats and seasons as the two explanatory variables (i.e. without interaction, adjusted $R^{2}=0.31, P<0.001$ ) was computed. A second linear model using the same variables was then computed, but, this time, considering an interaction between seasons and habitats (adjusted $\mathrm{R}^{2}=0.54, \mathrm{P}<0.001$ ). An ANOVA showed that including the interaction improved the model $(\mathrm{P}<0.001)$. Because the interaction between seasons and habitats was significant, these variables (and their interaction) were considered together instead of individually.

The extent to which spatiotemporal, soil condition, and soil function variables explained the variation in ASV richness was then assessed using a variation partitioning analysis (Peres-Neto et al., 2006; Legendre and Legendre, 2012). More specifically, the variation of ASV richness 
was partitioned into a spatiotemporal fraction (i.e. interaction between seasons and habitats), a soil function fraction, and a soil condition fraction. Generalized Linear Models (GLM) with ASV richness as response and six variables reflecting soil conditions alongside four variables reflecting soil functions as descriptors were used to assess the importance of soil condition and soil function variables within each season. Soil silt and clay content were removed before analyses because of collinearity.

\subsection{Beta diversity: ASV turnover among habitats and seasons}

In order to estimate the relative importance of the spatial and temporal turnover of ASV per habitat as well as at the floodplain scale (i.e. within and among habitats), an additive partitioning of total ASV diversity (gamma) into alpha, beta spatial, and beta temporal components was conducted. Through additive decomposition, $\beta$-diversity is explicitly an average amount of diversity just as is $\alpha$-diversity (Veech et al., 2002). This approach thus allows direct comparison of alpha and beta diversities which is particularly relevant for testing theoretical concepts and developing conservation and/or management applications. The additive partitioning of diversity was done following the method of Tylianakis et al. (2005) (see also: Veech et al., 2002; Crist et al., 2003). Alpha diversity $(\alpha)$ was defined as the mean number of ASV per plot per season. The temporal turnover in ASV between seasons was calculated for each plot $\left(\beta_{\text {TPlot }}\right)$ within a given habitat type as: the total number of ASV found within that plot (over the entire year) minus the mean number of ASV per season for that plot $(\alpha)$. Overall $\beta_{\mathrm{T}}$ was calculated as the mean $\beta_{\text {TPlot }}$ for a given habitat type. Spatial turnover $\left(\beta_{\mathrm{S}}\right)$ was calculated as the total number of ASV found within a habitat type over the entire year minus the mean number of ASV per plot of that habitat type (over the entire year). Therefore, the overall diversity of a habitat type can be described as $\gamma=\alpha+\beta_{\mathrm{T}}+\beta_{\mathrm{S}}$.

The drivers of community compositional changes were then investigated using PERMANOVA applied on a Bray-Curtis dissimilarity matrix (function ADONIS, R package "vegan"; Oksanen et al., 2015). Seasons (time), habitat (space), and their interaction (space-time) were used as explanatory variables. As for ASV richness, there was a significant space-time interaction (whole model: adjusted $\mathrm{R}^{2}=0.34, \mathrm{P}<0.001$; interaction term: adjusted $\left.\mathrm{R}^{2}=0.2, \mathrm{P}=0.001\right)$. The variation in ASV dissimilarity was then partitioned into a spatiotemporal fraction (i.e. interaction between seasons and habitats), a soil function fraction, and a soil condition fraction (Peres-Neto et al., 2006; Legendre and Legendre, 2012). Finally, the importance of soil condition and soil function variables within each season was explored using PERMANOVA with ASV dissimilarity as response and six soil condition and four function variables as descriptors. As for ASV richness, soil silt and clay content were removed before analyses because of collinearity.

\subsection{Indicator $A S V$}

Indicator ASVs were searched for each habitat in each season. The indicative value (IndVal) of each ASV for each habitat per season was assessed using the function "multipatt" of the R package "indicspecies" (De Cáceres, Legendre \& Moretti, 2010). This approach calculates an Indicator Value (IndVal) index to measure the association between a species (here ASV) and a group of sites (here habitats; Dufrêne and Legendre, 1997). The statistical significance of this relationship was assessed using a permutation test.

All statistical analyses were performed in $R$ version 3.6.1 ( $\mathrm{R}$ Development Core Team, 2018).

\section{Results}

\subsection{Metabarcoding of riparian soil microbial eukaryote environmental DNA}

A total of $11,280,627$ microbial eukaryote reads belonging to 14,900 distinct amplicon sequence variants (ASVs) were identified in the studied riparian soils. Overall, the dominant taxonomic groups in proportion of sequences were Fungi (36\%), Cercozoa (15\%), Ciliophora (8\%), Bacillariophyta (diatoms) (6\%), Chrysophyceae (3\%), and Peronosporomycetes (="Oomycetes") (3\%), while $30 \%$ of all ASVs belonged to less abundant taxonomic groups.

\subsection{Spatiotemporal changes in ASV richness}

ASV richness varied considerably over space and time (Fig. 1A). The most striking differences among habitats were observed in summer and winter. ASV richness was least variable among habitats in autumn where a large intra-habitat variation was observed. In agreement, the interactions of seasons and habitats explained an important part of the variation in ASV richness (adjusted $\mathrm{R}^{2}=0.36$; Fig. 1B). Part of this variation can be explained by changes in soil conditions (adjusted $\mathrm{R}^{2}=$ 0.1 ) and soil functions (adjusted $\mathrm{R}^{2}=0.08$ ). We also found strong difference in the importance and effect of soil conditions and functions within each season (Table 1).

\subsection{Spatiotemporal variability in soil microbial eukaryotic assemblages}

The turnover of species was higher among habitats $\left(\beta_{S}\right)$ than seasons $\left(\beta_{\mathrm{T}}\right)$ (Fig. 2A), indicating that the community composition of soil microbial eukaryotes varied more spatially than seasonally. The temporal turnover of species was higher than alpha diversity in all habitats. However, the temporal turnover was about half of the spatial turnover within each habitat. Furthermore, the relative importance of the spatial turnover of species increased at the floodplain scale highlighting the heterogeneity among habitats. We found a similar pattern for the six most abundant taxonomic groups with little variability among groups (Fig. S2). We further found that the interaction between habitat and seasons explained $14 \%$ of the variation in community composition whereas soil conditions and functions each explained about $2 \%$ of this variation (Fig. 2B). We also found strong changes in the importance of soil conditions and functions within each season (Table 2).

\subsection{Indicator ASVs}

We found several indicator ASVs for each habitat in each season, but with important differences in the number and type of indicators (Fig. 3). In spring and autumn, the number of indicator ASVs was clearly higher in Pasture. In winter, however, the highest number of indicators was observed in Gravel. We also observed differences among taxonomic groups. For example, diatoms were associated to Gravel in winter and Cercozoa were more frequently associated to the three habitats further away from to the river (Mixed forest, Willow forest, and Pasture).

\section{Discussion}

Soil microbial eukaryotes are highly diverse and play key roles in soil functioning (Geisen et al., 2016). Currently, however, the spatial and, especially, temporal patterns of soil microbial eukaryotic beta diversity remains poorly known and our main goal was to characterize these patterns and understand their drivers in a highly dynamic natural and complex ecosystem. Characterizing soil microbial eukaryotic spatiotemporal beta diversity will improve our understanding of community dynamics as well as our capacity to anticipate future changes in soil ecosystem structure and functions.

The present study is, to our knowledge, the first that presents a 


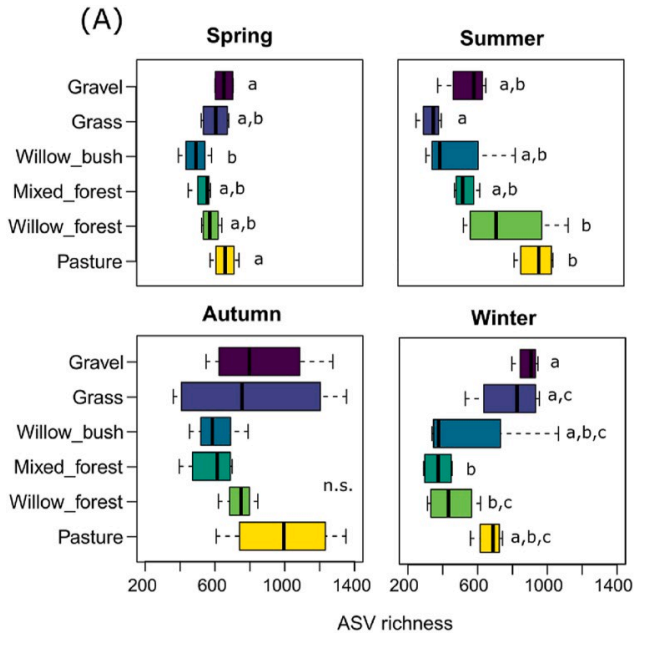

(B)

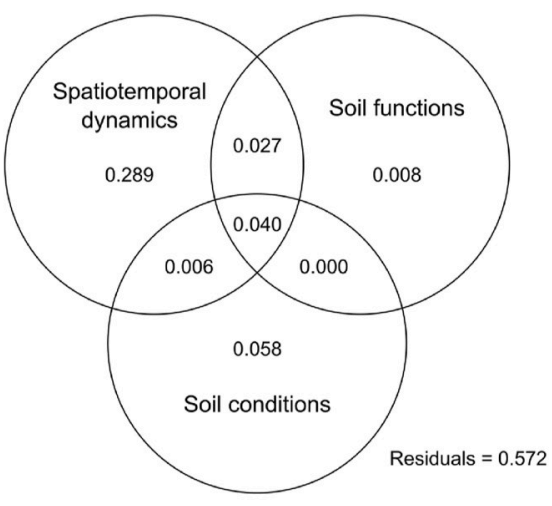

Fig. 1. (A) Changes in floodplain soil microeukaryotic amplicon sequence variants (ASV) richness among habitats per season. Letters indicate pairwise differences in mean (Tukey honest differences). Colors highlight the six different habitats. (B) Partitioning of the variation in ASV richness among spatiotemporal (36.2\%), soil condition (10.4\%), and soil function (7.5\%) components. (For interpretation of the references to color in this figure legend, the reader is referred to the Web version of this article.)

Table 1

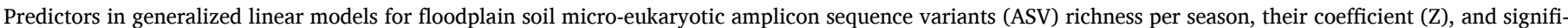

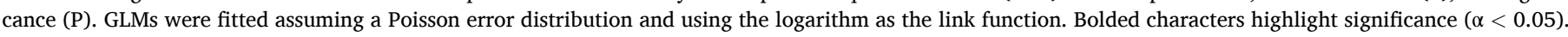

\begin{tabular}{|c|c|c|c|c|c|c|c|c|c|}
\hline & & \multicolumn{2}{|l|}{ Spring } & \multicolumn{2}{|l|}{ Summer } & \multicolumn{2}{|l|}{ Autumn } & \multicolumn{2}{|l|}{ Winter } \\
\hline & & \multicolumn{2}{|c|}{$\left(\mathrm{R}^{2}=0.56\right)$} & \multicolumn{2}{|c|}{$\left(\mathrm{R}^{2}=0.61\right)$} & \multicolumn{2}{|c|}{$\left(\mathrm{R}^{2}=0.51\right)$} & \multicolumn{2}{|c|}{$\left(\mathrm{R}^{2}=0.8\right)$} \\
\hline & & $\mathrm{Z}$ & $\mathrm{P}$ & $\mathrm{Z}$ & $\mathrm{P}$ & $\mathrm{Z}$ & $\mathrm{P}$ & $\mathrm{Z}$ & $\mathrm{P}$ \\
\hline \multirow{6}{*}{$\begin{array}{l}\text { Soil } \\
\text { conditions }\end{array}$} & Soil moisture & -2.446 & 0.014 & -12.461 & $>0.001$ & 1.837 & 0.066 & 5.745 & $>0.001$ \\
\hline & Soil temperature & 2.082 & 0.037 & 21.63 & $>0.001$ & -1.459 & 0.145 & 2.149 & 0.032 \\
\hline & Sand & 1.802 & 0.071 & -10.511 & $>0.001$ & -10.102 & $>0.001$ & 0.177 & 0.859 \\
\hline & Organic carbon & -4.215 & $>0.001$ & -13.692 & $>0.001$ & -12.639 & $>0.001$ & -3.73 & $>0.001$ \\
\hline & Available phosphorus & 3.118 & 0.002 & 1.183 & 0.237 & 13.147 & $>0.001$ & 12.863 & $>0.001$ \\
\hline & Total nitrogen & 3.327 & 0.001 & 13.936 & $>0.001$ & 4.845 & $>0.001$ & -1.447 & 0.148 \\
\hline \multirow{4}{*}{$\begin{array}{l}\text { Soil } \\
\text { functions }\end{array}$} & Basal respiration & -2.292 & 0.022 & 12.225 & $>0.001$ & 9.432 & $>0.001$ & -4.565 & $>0.001$ \\
\hline & Enzymatic activity & 2.684 & 0.007 & 3.735 & $>0.001$ & 0.657 & 0.511 & -8.354 & $>0.001$ \\
\hline & Microbial carbon & 5.432 & $>0.001$ & 9.289 & $>0.001$ & -16.266 & $>0.001$ & 4.241 & $>0.001$ \\
\hline & Microbial nitrogen & -2.167 & 0.030 & -0.531 & 0.596 & 12.318 & $>0.001$ & 0.613 & 0.540 \\
\hline
\end{tabular}

(A)

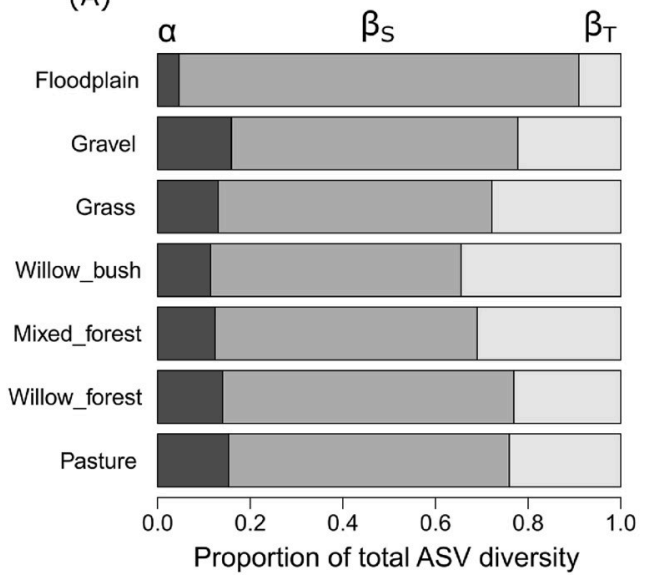

(B)

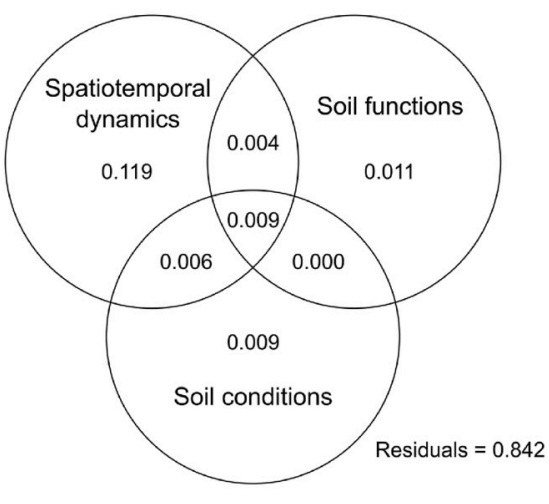

Fig. 2. Spatiotemporal turnover of floodplain soil micro-eukaryotic taxa (amplicon sequence variants - ASV). (A) Partitioning of total diversity $(\gamma)$ into local diversity $(\alpha)$, temporal species turnover $\left(\beta_{\mathrm{T}}\right)$, and spatial species turnover $\left(\beta_{\mathrm{S}}\right)$ per habitat $(\gamma=\alpha$ $+\beta_{\mathrm{T}}+\beta_{\mathrm{S}}$ ). This analysis shows a higher spatial than temporal turnover of soil microbial eukaryotic taxa both at the floodplain scale and within habitats. (B) Partitioning of the variation in ASV community composition among spatiotemporal (13.8\%), soil condition (2.4\%), and soil function (2.4\%) components. detailed assessment of soil microbial eukaryote ASV richness and spatiotemporal beta diversity in riparian soils. Soil microbial eukaryotic richness and beta diversity were surveyed using a DNA-based approach over an entire year along a gradient of very heterogeneous habitats encompassing strong changes in flood dynamics, vegetation, and soil conditions and functions. Our results highlight a strikingly important contribution of beta diversity to total microbial eukaryotic diversity within the floodplain. Specifically, the spatial and, to a lesser extent, temporal turnover of ASVs are the main sources of microbial eukaryotic diversity within the floodplain. This contrasts with previous studies based on microscopic observations highlighting a high local diversity of microbial eukaryotes and a relatively high local/global species ratio of soil microbial eukaryotes (e.g. Finlay, 2002; Fenchel and Finlay, 2004). Such studies, however, characterized a limited fraction of the total diversity by lumping large numbers of genetically very different organisms into single morphospecies (Bass et al., 2007; Heger et al., 2013) which likely greatly underestimates the importance of beta diversity (Singer et al., 2018). The advent of high throughput metabarcoding studies now 
Table 2

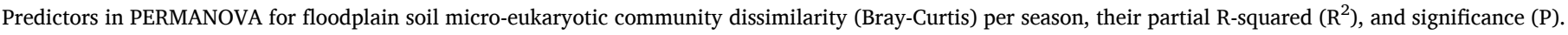
Bolded characters highlight significance $(\alpha<0.05)$.

\begin{tabular}{|c|c|c|c|c|c|c|c|c|c|}
\hline & & \multicolumn{2}{|l|}{ Spring } & \multicolumn{2}{|c|}{ Summer } & \multicolumn{2}{|c|}{ Autumn } & \multicolumn{2}{|c|}{ Winter } \\
\hline & & \multicolumn{2}{|c|}{$\left(R^{2}=0.49\right)$} & \multicolumn{2}{|c|}{$\left(\mathrm{R}^{2}=0.47\right)$} & \multicolumn{2}{|c|}{$\left(R^{2}=0.5\right)$} & \multicolumn{2}{|c|}{$\left(\mathrm{R}^{2}=0.49\right)$} \\
\hline & & $\mathrm{R}^{2}$ & $\mathrm{P}$ & $\mathrm{R}^{2}$ & $\mathrm{P}$ & $\mathrm{R}^{2}$ & $\mathrm{P}$ & $\mathrm{R}^{2}$ & $\mathrm{P}$ \\
\hline \multirow{6}{*}{$\begin{array}{l}\text { Soil } \\
\text { conditions }\end{array}$} & Soil moisture & 0.055 & 0.044 & 0.047 & 0.205 & 0.064 & 0.014 & 0.037 & 0.583 \\
\hline & Soil temperature & 0.075 & 0.002 & 0.058 & 0.073 & 0.074 & 0.007 & 0.038 & 0.49 \\
\hline & Sand & 0.060 & 0.018 & 0.056 & 0.099 & 0.044 & 0.192 & 0.099 & 0.001 \\
\hline & Organic carbon & 0.043 & 0.249 & 0.039 & 0.463 & 0.041 & 0.302 & 0.040 & 0.384 \\
\hline & Available phosphorus & 0.038 & 0.536 & 0.044 & 0.294 & 0.048 & 0.13 & 0.040 & 0.366 \\
\hline & Total nitrogen & 0.042 & 0.273 & 0.045 & 0.265 & 0.046 & 0.153 & 0.037 & 0.61 \\
\hline \multirow{4}{*}{$\begin{array}{l}\text { Soil } \\
\text { functions }\end{array}$} & Basal respiration & 0.034 & 0.84 & 0.049 & 0.197 & 0.053 & 0.064 & 0.051 & 0.052 \\
\hline & Enzymatic activity & 0.053 & 0.042 & 0.036 & 0.663 & 0.038 & 0.444 & 0.055 & 0.033 \\
\hline & Microbial carbon & 0.039 & 0.452 & 0.060 & 0.071 & 0.046 & 0.169 & 0.046 & 0.147 \\
\hline & Microbial nitrogen & 0.049 & 0.078 & 0.037 & 0.543 & 0.042 & 0.292 & 0.049 & 0.086 \\
\hline
\end{tabular}
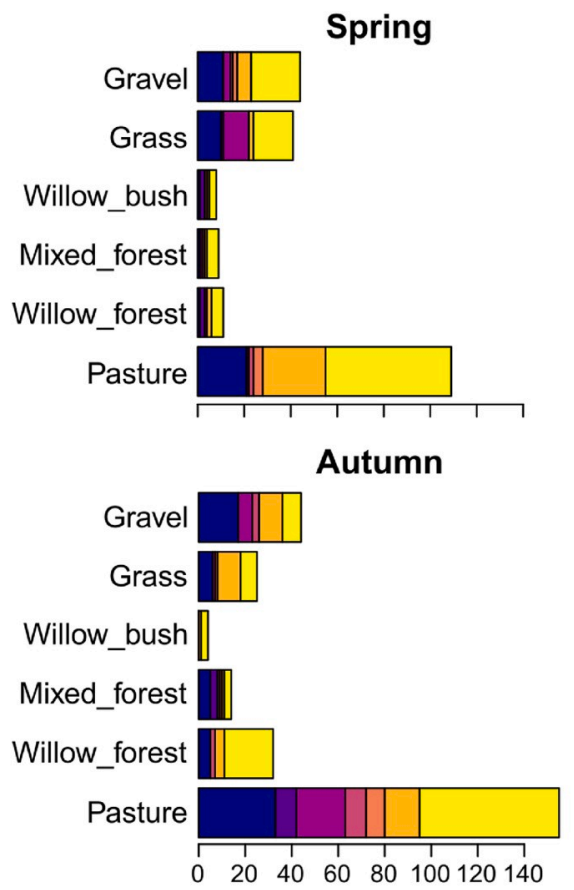

Number of indicative taxa
Summer

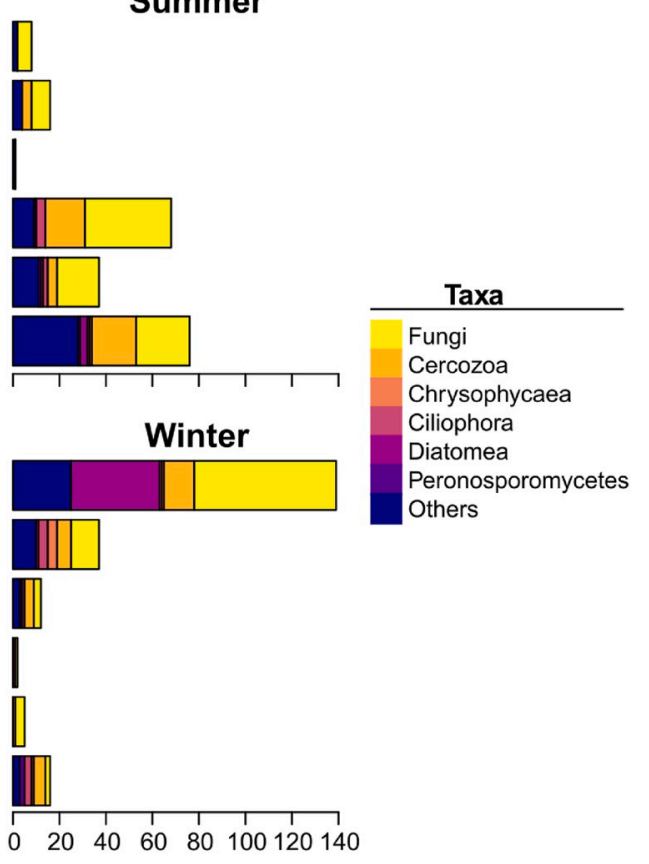

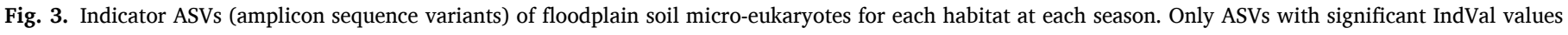

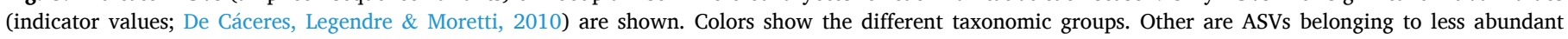
taxonomic groups. (For interpretation of the references to color in this figure legend, the reader is referred to the Web version of this article.)

allows a more complete and objective assessment of biodiversity patterns and a reassessment of existing knowledge. In a study of Neotropical rainforest soils, Lentendu et al. (2018) found a high alpha and low beta diversity for several groups of microbial eukaryotes. However, this study was done in rainforest habitats only (i.e. it does not include a gradient of habitats ranging from bare soils to relatively dense forests contrary to our study) and was based on a single sampling campaign, thus not considering the temporal aspect of beta diversity, which might explain the low beta diversity observed. In contrast, Behnke et al. (2010), studying the spatiotemporal changes of protist communities in marine environments, found that the temporal variation was as pronounced as the spatial differences between depths. And Chénard et al. (2019) observed a higher seasonal variation in coastal waters exposed to the influence of the monsoon. In our case, the temporal variation is less pronounced than the spatial one. We attribute this difference as reflecting the higher spatial heterogeneity of soils as compared to marine ecosystems.

We observed a high spatiotemporal complexity in the edaphic drivers of soil microbial eukaryotic alpha and beta diversities. Indeed, a strong interaction between seasons and habitats determines ASV richness and beta diversity. And, seasonal analyses of the drivers of ASV richness and beta diversity show important shifts in variable importance $\left(R^{2}\right)$ as well as shifts in the direction of the relationship (Tables 1 and 2). While other studies, in agreement with our results, have highlighted the importance of soil water availability (Bates et al., 2013; Geisen et al., 2014; Fiore-Donno et al., 2019), C and N cycling (Krashevska et al., 2010), and soil temperature (Tsyganov et al., 2011) as drivers of microbial eukaryote taxa, to our knowledge no study has assessed the importance of proxies for soil ecosystem functioning alongside soil conditions and the seasonal shifts in these drivers. These shifts are likely to have important consequences for biogeochemical processes in soil ecosystems (Levy-Booth et al., 2019). For example, soil moisture has negative effect on richness in spring and summer and a positive effect on richness in winter. In agreement with these results, Geisen et al. (2014) showed a non-linear effect of soil water availability on soil protists suggesting maximum abundance of soil protists at intermediate levels of soil water 
availability. Most of the other studied soil variables showed complex seasonal shifts in importance and/or effects that likely reflects flooding dynamics, and biogeochemical cycles in the soil ecosystems. Interestingly, we observed a floodplain-scale homogenization of soil microbial eukaryotic communities in autumn (i.e. no significant differences in composition among habitats). This homogenization likely resulted from floods occurring shortly before the sampling campaign. Floods can bring propagules from outside the floodplain and move soil material among habitats resulting in increased dispersal at the floodplain scale. Dispersal in metacommunities has indeed the potential to increase immigration in local communities resulting in homogenization at the metacommunity scale (Fodelianakis et al., 2019).

The present study also highlights the role of deterministic processes for soil microbial eukaryotic diversity. The high beta diversity and the identification of several ASVs as specific to a particular season and habitat (Fig. 3) suggests a direct response to environmental heterogeneity, as reported for testate amoebae (Fournier et al., 2012b) and macro-invertebrates at the same site (Fournier et al., 2015). Previous studies have already highlighted that different habitat types (e.g., seawater versus soils) harbour different suites of microbial eukaryotes (Bates et al., 2013). And the role of a variety of environmental factors in determining soil microbial eukaryotic community structure and richness is well established (Krashevska et al., 2010; Bates et al., 2013; Geisen et al., 2014; Fiore-Donno et al., 2019). As such, it is likely that species sorting is a major driver of soil microbial eukaryotic diversity patterns (Leibold et al., 2004; Pandit et al., 2009; Singer et al., 2018). However, at a finer scale, soil microbial eukaryotes were also shown to have a stochastic distribution in boreal forest soils (Bahram et al., 2016), a result most likely due to the short environmental gradient sampled. Thus, the degree of environmental heterogeneity covered in a study likely determines the inferred strength of stochastic versus deterministic processes for the assembly of soil microbial eukaryotic communities with the importance of deterministic niche-based processes increasing together with heterogeneity (e.g. along environmental gradients) (Jassey et al., 2011).

Our results contrast with a previous study at the same study site showing a much higher temporal than spatial variation of bacterial communities (Samaritani et al., 2017). Studies showing a higher spatial than temporal beta diversity of soil bacteria also exists (e.g. Lauber et al., 2013). However, these studies were conducted over larger spatial extent and the importance of dispersal limitation is thus likely to be higher than in our study. Two interrelated hypotheses can explain the observed differences in spatiotemporal beta diversity between soil microbial eukaryotes and bacteria. Microbial eukaryotes typically have longer life span and generation time than bacteria. Despite large variation in life strategies within micro-eukaryotes and within bacteria, microbial eukaryotes can, in general, be considered as K-strategists while bacteria would then be r-strategists, and thus the diversity patterns of microbial eukaryotes should be driven (and explained) by local adaptation ( $\mathrm{r}-\mathrm{K}$ selection; MacArthur and Wilson, 1967; Pianka, 1970). In addition, microbial eukaryotes might have a lower passive dispersal capacity (e.g. by wind and flood) than bacteria due to their larger (by microbial standard) size (Wilkinson et al., 2012). It can thus be expected that local niche-based processes and dispersal limitations play a larger role for protists than for bacteria. In agreement with this, a recent study in marine ecosystems highlighted lower sorting/dispersal effect ratios for bacterial communities as compared to protist communities (Wu et al., 2018).

Our study, however, did not consider some potentially important factors for soil microbial eukaryotic diversity. For example, seasonal shifts from bacteria-based to fungal-based decomposition pathways should modify the availability of food resources potentially causing shifts in the composition of the phagotrophic component of the soil microbial eukaryotic communities. Indeed, previous studies have identified highly specialized fungal feeder microbial eukaryote taxa (Petz et al., 1985; Foissner, 1999) that would be negatively impacted by a decrease in the abundance of fungi in the soil. However, some protists are generalist feeders that are also capable of facultative mycophagy (Geisen et al., 2016). Furthermore, some protists are autotrophs, mixotrophs or osmotrophs and are thus not or only marginally affected by the relative abundance of fungi vs bacteria. In any case, the lower temporal than spatial variation suggest that eukaryotes can cope with potential seasonal shifts in prey availability either by being flexible in their feeding source or by encysting. More specific investigations are needed to understand the implications of our results for the whole microbial foodweb. In addition, studies at larger spatial scale or experimental approaches might complement our results about the role of dispersal for beta diversity and its changes across spatial scales. Similarly, our study does not consider the inter-annual or intra-seasonal variability in soil microbial communities which are expected to be smaller than the inter-seasonal variability but might still represent a significant fraction of the total diversity. And, because our approach is based on eDNA, our data might include ASVs derived from extracellular DNA, encysted, or inactive organisms. Finally, our study raises the question of the role of floods for microbial taxa dispersal within the floodplain. Indeed, floods can bring propagules from outside the floodplain and move soil material among habitats thus increasing dispersal and stochasticity potentially leading to homogenization of community composition at the floodplain scale. As such, one can expect low spatial structuring of communities. However, our results do not support this view and rather point toward the importance of local environmental filtering for community structure.

\section{Conclusions}

We demonstrated the existence of both spatial and temporal turnover in floodplain soil microbial eukaryotic diversity mirroring the spatiotemporal patterns of biogeochemical processes in these ecosystems. Our results also illustrate the value of spatial monitoring of soil biodiversity across habitats within a complex ecosystem. The observed temporal dynamics illustrate the value of seasonal sampling for biodiversity assessment to accurately estimate the diversity and the complexity of assembly processes of soil microbial communities. Sound measurements of the patterns and drivers of soil microbial diversity is needed to understand the relationships between biodiversity and ecosystem functions. This, in turn, allows to assess the impact of environmental changes and management options including restoration efforts on a range of ecosystems.

\section{Conflicts of interest}

The authors declare no conflict of interest regarding the publication of this article.

\section{Declaration of competing interest}

The authors declare that they have no known competing financial interests or personal relationships that could have appeared to influence the work reported in this paper.

\section{Acknowledgements}

This research was funded by the ETH Competence Center Environment and Sustainability (project NatuRe RECORD) to EM, with additional support from the Swiss National Science Foundation (PBNEP3_140195) to ES, the office for equal opportunity of the University of Neuchâtel to ES and from HES-SO (project 78046, MaLDiveS) to TH and BF. EL acknowledges the program "Atracción de Talentos" from the Council for Education, Youth and Sport of the Community of Madrid (grant 2017-T1/AMB-5210). CVWS would also like to thanks the Research Council of Norway (projects 270252 Climarctic and 256132 Methanobase). We thank the colleagues from WSL Birmensdorf and 
Lausanne, University of Neuchâtel, Brown University, and Changins (HES-SO) for valuable collaborations, help and inputs to various parts of this study.

\section{Appendix A. Supplementary data}

Supplementary data to this article can be found online at https://doi. org/10.1016/j.soilbio.2020.107842.

\section{References}

Acosta-Mercado, D., Lynn, D.H., 2002. A preliminary assessment of spatial patterns of soil ciliate diversity in two subtropical forests in Puerto Rico and its implications for designing an appropriate sampling approach. Soil Biology and Biochemistry 34, 1517-1520.

Adam, G., Duncan, H., 2001. Development of a sensitive and rapid method for the measurement of total microbial activity using fluorescein diacetate (FDA) in a range of soils. Soil Biology and Biochemistry 33, 943-951.

Amaral-Zettler, L.A., McCliment, E.A., Ducklow, H.W., Huse, S.M., 2009. A method for studying protistan diversity using massively parallel sequencing of V9 hypervariable regions of small-subunit ribosomal RNA genes. PloS One 4, e6372.

Astorga, A., Oksanen, J., Luoto, M., Soininen, J., Virtanen, R., Muotka, T., 2012. Distance decay of similarity in freshwater communities: do macro- and microorganisms follow the same rules? Global Ecology and Biogeography 21, 365-375.

Bahram, M., Kohout, P., Anslan, S., Harend, H., Abarenkov, K., Tedersoo, L., 2016. Stochastic distribution of small soil eukaryotes resulting from high dispersal and drift in a local environment. The ISME Journal 10, 885.

Baldwin, D.S., Colloff, M.J., Rees, G.N., Chariton, A.A., Watson, G.O., Court, L.N. Hartley, D.M., Morgan, M.J., King, A.J., Wilson, J.S., Hodda, M., Hardy, C.M., 2013. Impacts of inundation and drought on eukaryote biodiversity in semi-arid floodplain soils. Molecular Ecology 22, 1746-1758.

Barrios, E., 2007. Soil biota, ecosystem services and land productivity. Ecological Economics 64, 269-285.

Bass, D., Richards, T.A., Matthai, L., Marsh, V., Cavalier-Smith, T., 2007. DNA evidence for global dispersal and probable endemicity of protozoa. BMC Evolutionary Biology 7, 162 .

Bates, S.T., Clemente, J.C., Flores, G.E., Walters, W.A., Parfrey, L.W., Knight, R., Fierer, N., 2013. Global biogeography of highly diverse protistan communities in soil. The ISME Journal 7, 652-659.

Behnke, A., Barger, K.J., Bunge, J., Stoeck, T., 2010. Spatio-temporal variations in protistan communities along an $\mathrm{O}_{2} / \mathrm{H}_{2} \mathrm{~S}$ gradient in the anoxic Framvaren Fjord (Norway). FEMS Microbiology Ecology 72, 89-102.

Binkley, D., Suarez, F., Stottlemyer, R., Caldwell, B., 1997. Ecosystem development on terraces along the Kugururok River, northwest Alaska. Écoscience 4, 311-318.

Bolyen, E., Rideout, J.R., Dillon, M.R., Bokulich, N.A., Abnet, C., Al-Ghalith, G.A., et al., 2018. Qiime 2. Nature Biotechnology 37, 852-857.

Bonkowski, M., 2004. Protozoa and plant growth: the microbial loop in soil revisited. New Phytologist 162, 617-631.

Callahan, B.J., McMurdie, P.J., Rosen, M.J., Han, A.W., Johnson, A.J.A., Holmes, S.P., 2016. DADA2: high-resolution sample inference from Illumina amplicon data. Nature Methods 13, 581.

Chénard, C., Wijaya, W., Vaulot, D., Lopes dos Santos, A., Martin, P., Kaur, A., Lauro, F. M., 2019. Temporal and spatial dynamics of Bacteria, Archaea and protists in equatorial coastal waters. Scientific Reports 9, 16390.

Crist, T.O., Veech, J.A., Gering, J.C., Summerville, K.S., 2003. Partitioning species diversity across landscapes and regions: a hierarchical analysis of $\alpha, \beta$, and $\gamma$ diversity. The American Naturalist 162, 734-743.

De Cáceres, M., Legendre, P., Moretti, M., 2010. Improving indicator species analysis by combining groups of sites. Oikos 119, 1674-1684.

de Vries, F.T., Thébault, E., Liiri, M., Birkhofer, K., Tsiafouli, M.A., Bjørnlund, L., Bracht Jørgensen, H., Brady, M.V., Christensen, S., de Ruiter, P.C., d'Hertefeldt, T., Frouz, J., Hedlund, K., Hemerik, L., Hol, W.H.G., Hotes, S., Mortimer, S.R., Setälä, H., Sgardelis, S.P., Uteseny, K., van der Putten, W.H., Wolters, V., Bardgett, R. D., 2013. Soil food web properties explain ecosystem services across European land use systems. Proceedings of the National Academy of Sciences 110, 14296-14301.

Dufrêne, M., Legendre, P., 1997. Species assemblages and indicator species: the need for a flexible asymmetrical approach. Ecological Monographs 67, 345-366.

Fenchel, T., Finlay, B.J., 2004. The ubiquity of small species: patterns of local and global diversity. BioScience 54, 777-784.

Fernández, L.D., Fournier, B., Rivera, R., Lara, E., Mitchell, E.A.D., Hernández, C.E., 2016. Water-energy balance, past ecological perturbations and evolutionary constraints shape the latitudinal diversity gradient of soil testate amoebae in southwestern South America. Global Ecology and Biogeography 25, 1216-1227.

Finlay, B.J., 2002. Global dispersal of free-living microbial eukaryote species. Science 296, 1061-1063.

Fiore-Donno, A.M., Richter-Heitmann, T., Degrune, F., Dumack, K., Regan, K.M., Marhan, S., Boeddinghaus, R.S., Rillig, M.C., Friedrich, M.W., Kandeler, E., Bonkowski, M., 2019. Functional traits and spatio-temporal structure of a major group of soil protists (Rhizaria: Cercozoa) in a temperate grassland. Frontiers in Microbiology 10, 1-12.

Fodelianakis, S., Lorz, A., Valenzuela-Cuevas, A., Barozzi, A., Booth, J.M., Daffonchio, D. 2019. Dispersal homogenizes communities via immigration even at low rates in a simplified synthetic bacterial metacommunity. Nature Communications 10, 1314.
Foissner, W., 1999. Description of two new, mycophagous soil ciliates (Ciliophora, Colpodea): Fungiphrya strobling, n. sp. and Grossglockneria ovata n. sp. The Journal of Eukaryotic Microbiology 46, 34-42.

Foissner, W., 2006. Biogeography and dispersal of micro-organisms: a review emphasizing protists. Acta Protozoologica 45, 111-136.

Foissner, W., Chao, A., Katz, L.A., 2007. Diversity and geographic distribution of ciliates (Protista: Ciliophora). In: Hawksworth, D.L., Foissner, W. (Eds.), Protist Diversity and Geographical Distribution. Springer, pp. 111-129.

Fournier, B., Gillet, F., Le Bayon, R.-C., Mitchell, E.A.D., Moretti, M., 2015. Functional responses of multitaxa communities to disturbance and stress gradients in a restored floodplain. Journal of Applied Ecology 52, 1364-1373.

Fournier, B., Guenat, C., Bullinger-Weber, G., Mitchell, E.A.D., 2013. Spatio-temporal heterogeneity of riparian soil morphology in a restored floodplain. Hydrology and Earth System Sciences 17, 4031-4042.

Fournier, B., Malysheva, E., Mazei, Y., Moretti, M., Mitchell, E.A.D., 2012a. Toward the use of testate amoeba functional traits as indicator of floodplain restoration success. European Journal of Soil Biology 49, 85-91.

Fournier, B., Samaritani, E., Shrestha, J., Mitchell, E.A.D., Le Bayon, R.C., 2012b. Patterns of earthworm communities and species traits in relation to the perturbation gradient of a restored floodplain. Applied Soil Ecology 59, 87-95.

Frey, B., Stemmer, M., Widmer, F., Luster, J., Sperisen, C., 2006. Microbial activity and community structure of a soil after heavy metal contamination in a model forest ecosystem. Soil Biology and Biochemistry 38, 1745-1756.

Gee, G.W., Bauder, J.W., 1986. Particle-size analysis. In: Klute, A. (Ed.), Methods of Soil Analysis: Part 1 - Physical and Mineralogical Methods. American Society of Agronomy/Soil Science Society of America, Madison, Wisconsin, pp. 383-411.

Geisen, S., 2016. The bacterial-fungal energy channel concept challenged by enormous functional versatility of soil protists. Soil Biology and Biochemistry 102, 22-25.

Geisen, S., Bandow, C., Römbke, J., Bonkowski, M., 2014. Soil water availability strongly alters the community composition of soil protists. Pedobiologia 57, 205-213.

Geisen, S., Koller, R., Hünninghaus, M., Dumack, K., Urich, T., Bonkowski, M., 2016. The soil food web revisited: diverse and widespread mycophagous soil protists. Soil Biology and Biochemistry 94, 10-18.

Gering, J.C., Crist, T.O., Veech, J.A., 2003. Additive partitioning of species diversity across multiple spatial scales: implications for regional conservation of biodiversity. Conservation Biology 17, 488-499.

Heger, T.J., Mitchell, E.A.D., Leander, B.S., 2013. Holarctic phylogeography of the testate amoeba Hyalosphenia papilio (Amoebozoa: Arcellinida) reveals extensive genetic diversity explained more by environment than dispersal limitation. Molecular Ecology 22, 5172-5184.

Iuss Working Group Wrb, 2006. World Reference Base for Soil Resources. Food and agriculture organization of the United Nations (FAO), Rome.

Jassey, V.E., Chiapusio, G., Mitchell, E.A.D., Binet, P., Toussaint, M.-L., Gilbert, D., 2011. Fine-scale horizontal and vertical micro-distribution patterns of testate amoebae along a narrow fen/bog gradient. Microbial Ecology 61, 374-385.

Krashevska, V., Maraun, M., Ruess, L., Scheu, S., 2010. Carbon and nutrient limitation of soil microorganisms and microbial grazers in a tropical montane rain forest. Oikos 119, 1020-1028.

Kuo, S., 1996. Phosphorus. In: Sparks, D.L. (Ed.), Methods of Soil Analysis: Part 3 Chemical Methods. Soil Science Society of America, Madison, Wisconsin, pp. 869-920.

Lamentowicz, M., Bragazza, L., Buttler, A., Jassey, V.E.J., Mitchell, E.A.D., 2013. Seasonal patterns of testate amoeba diversity, community structure and species-environment relationships in four Sphagnum-dominated peatlands along a $1300 \mathrm{~m}$ altitudinal gradient in Switzerland. Soil Biology and Biochemistry 67, 1-11.

Lara, E., Roussel-Delif, L., Fournier, B., Wilkinson, D.M., Mitchell, E.A.D., 2016. Soil microorganisms behave like macroscopic organisms: patterns in the global distribution of soil euglyphid testate amoebae. Journal of Biogeography 43, $520-532$.

Lauber, C.L., Ramirez, K.S., Aanderud, Z., Lennon, J., Fierer, N., 2013. Temporal variability in soil microbial communities across land-use types. The ISME Journal 7, 1641-1650.

Legendre, P., Legendre, L., 2012. Numerical Ecology. Elsevier, Amsterdam.

Leibold, M.A., Holyoak, M., Mouquet, N., Amarasekare, P., Chase, J.M., Hoopes, M.F., Holt, R.D., Shurin, J.B., Law, R., Tilman, D., Loreau, M., Gonzalez, A., 2004. The metacommunity concept: a framework for multi-scale community ecology. Ecology Letters 7, 601-613.

Lentendu, G., Mahé, F., Bass, D., Rueckert, S., Stoeck, T., Dunthorn, M., 2018. Consistent patterns of high alpha and low beta diversity in tropical parasitic and free-living protists. Molecular Ecology 27, 2846-2857.

Levy-Booth, D.J., Giesbrecht, I.J.W., Kellogg, C.T.E., Heger, T.J., D’Amore, D.V., Keeling, P.J., Hallam, S.J., Mohn, W.W., 2019. Seasonal and ecohydrological regulation of active microbial populations involved in $\mathrm{DOC}, \mathrm{CO}_{2}$, and $\mathrm{CH}_{4}$ fluxes in temperate rainforest soil. The ISME Journal 13, 950-963.

MacArthur, R.H., Wilson, E.O., 1967. The Theory of Island Biogeography. Princeton University Press, New Jersey.

Martin, M., 2011. Cutadapt removes adapter sequences from high-throughput sequencing reads. EMBnet J. 17, 10-12.

Mitchell, E.A.D., Borcard, D., Buttler, A.J., Grosvernier, P., Gilbert, D., Gobat, J.-M. 2000. Horizontal distribution patterns of testate amoebae (Protozoa) in a Sphagnum magellanicum carpet. Microbial Ecology 39, 290-300.

Oksanen, J., Blanchet, F.G., Kindt, R., Legendre, P., Minchin, P.R., O'Hara, Simpson, G. L., Solymos, P., Stevens, M.H., Wagner, H., 2015. Vegan: Community Ecology Package. 
Pandit, S.N., Kolasa, J., Cottenie, K., 2009. Contrasts between habitat generalists and specialists: an empirical extension to the basic metacommunity framework. Ecology 90, 2253-2262.

Peres-Neto, P.R., Legendre, P., Dray, S., Borcard, D., 2006. Variation partitioning of species data matrices: estimation and comparison of fractions. Ecology 87, 2614-2625.

Petz, W., Foissner, W., Adam, H., 1985. Culture, food selection and growth rate in the mycophagous ciliate Grossglockneria acuta (Foissner, 1980): first evidence of autochthonous soil ciliates. Soil Biology and Biochemistry 17, 871-875.

Pianka, E.R., 1970. On r- and K-Selection. The American Naturalist 104, 592-597.

Quast, C., Pruesse, E., Yilmaz, P., Gerken, J., Schweer, T., Yarza Peplies, J., Glöckner, F. O., 2012. The SILVA ribosomal RNA gene database project: improved data processing and web-based tools. Nucleic Acids Research 41, D590-D596.

R Development Core Team, 2018. R: A Language and Environment for Statistical Computing. R Foundation for Statistical Computing, Vienna, Austria.

Rieder, S.R., Brunner, I., Daniel, O., Liu, B., Frey, B., 2013. Methylation of mercury in earthworms and the effect of mercury on the associated bacterial communities. Plos One 8, e61215.

Samaritani, E., Mitchell, E.A.D., Rich, J., Shrestha, J., Fournier, B., Frey, B., 2017. Soil bacterial communities and ecosystem functioning change more strongly with season than habitat in a restored floodplain. Applied Soil Ecology 112, 71-78.

Samaritani, E., Shrestha, J., Fournier, B., Frossard, E., Gillet, F., Guenat, C., Niklaus, P.A., Pasquale, N., Tockner, K., Mitchell, E.A.D., Luster, J., 2011. Heterogeneity of soil carbon pools and fluxes in a channelized and a restored floodplain section (Thur River, Switzerland). Hydrology and Earth System Sciences 15, 1757-1769.

Schirmer, M., Luster, J., Linde, N., Perona, P., Mitchell, E.A.D., Barry, Hollender, J., Cirpka, O.A., Schneider, P., Vogt, T., 2014. Morphological, hydrological, biogeochemical and ecological changes and challenges in river restoration-the Thur River case study. Hydrology and Earth System Sciences 18, 2449-2462.

Schmidt, F.A., Ribas, C.R., Sobrinho, T.G., Ubaidillah, R., Schoereder, J.H., Clough, Y., Tscharntke, T., 2017. Similar alpha and beta diversity changes in tropical ant communities, comparing savannas and rainforests in Brazil and Indonesia. Oecologia 185, 487-498.

Schnürer, J., Rosswall, T., 1982. Fluorescein diacetate hydrolysis as a measure of total microbial activity in soil and litter. Applied and Environmental Microbiology 43, 1256-1261.

Sedell, J.R., Richey, J.E., Swanson, F.J., 1989. The river continuum,concept: a basis for the expected ecosystem behavior of very large rivers?. In: Proceedings of the International Large River Symposium, 106. Canadian Special Publication of Fisheries and Aquatic Sciences, pp. 49-55.

Simon, M., López-García, P., Deschamps, P., Moreira, D., Restoux, G., Bertolino, P., Jardillier, L., 2015. Marked seasonality and high spatial variability of protist communities in shallow freshwater systems. The ISME Journal 9, 1941.
Singer, D., Kosakyan, A., Seppey, C.V., Pillonel, A., Fernández, L.D., Fontaneto, D., Mitchell, E.A.D., Lara, E., 2018. Environmental filtering and phylogenetic clustering correlate with the distribution patterns of cryptic protist species. Ecology 99, 904-914.

Sisson, C., Gulla-Devaney, B., Katz, L.A., Grattepanche, J.-D., 2018. Seed bank and seasonal patterns of the eukaryotic SAR (Stramenopila, Alveolata and Rhizaria) clade in a New England vernal pool. Journal of Plankton Research 40, 376-390.

Söderström, B., 1977. Vital staining of fungi in pure cultures and in soil with fluorescein diacetate. Soil Biology and Biochemistry 9, 59-63.

Taberlet, P., Coissac, E., Pompanon, F., Brochmann, C., Willerslev, E., 2012. Towards next-generation biodiversity assessment using DNA metabarcoding. Molecular Ecology 21, 2045-2050.

Tedersoo, L., Bahram, M., Põlme, S., Kõljalg, U., Yorou, N.S., Wijesundera, R., Ruiz, L., et al., 2014. Global diversity and geography of soil fungi. Science 346, 1256688.

Tsyganov, A.N., Nijs, I., Beyens, L., 2011. Does climate warming stimulate or inhibit soil protist communities? A test on testate amoebae in high-arctic tundra with free-air temperature increase. Protist 162, 237-248.

Tuomisto, H., 2010. A diversity of beta diversities: straightening up a concept gone awry. Part 1. Defining beta diversity as a function of alpha and gamma diversity. Ecography 33, 2-22.

Tylianakis, J.M., Klein, A.-M., Tscharntke, T., 2005. Spatiotemporal variation in the diversity of Hymenoptera across a tropical habitat gradient. Ecology 86, 3296-3302.

Vance, E.D., Brookes, P.C., Jenkinson, D.S., 1987. An extraction method for measuring soil microbial biomass C. Soil Biology and Biochemistry 19, 703-707.

Veech, J.A., Summerville, K.S., Crist, T.O., Gering, J.C., 2002. The additive partitioning of species diversity: recent revival of an old idea. Oikos 99, 3-9.

Wagner, H.H., Wildi, O., Ewald, K.C., 2000. Additive partitioning of plant species diversity in an agricultural mosaic landscape. Landscape Ecology 15, 219-227.

Whittaker, R.H., 1960. Vegetation of the siskiyou mountains, Oregon and California. Ecological Monographs 30, 279-338.

Wilkinson, D.M., Koumoutsaris, S., Mitchell, E.A.D., Bey, I., 2012. Modelling the effect of size on the aerial dispersal of microorganisms. Journal of Biogeography 39, 89-97.

Woolsey, S., Capelli, F., Gonser, T., Hoehn, E., Hostmann, M., Junker, B., Paetzold, A., Roulier, C., Schweizer, S., Tiegs, S.D., 2007. A strategy to assess river restoration success. Freshwater Biology 52, 752-769.

Wu, W., Lu, H.-P., Sastri, A., Yeh, Y.-C., Gong, G.-C., Chou, W.-C., Hsieh, C.-H., 2018. Contrasting the relative importance of species sorting and dispersal limitation in shaping marine bacterial versus protist communities. The ISME Journal 12, 485-494.

Zhao, Z.-B., He, J.-Z., Geisen, S., Han, L.-L., Wang, J.-T., Shen, J.-P., Wei, W.X., Fang, Y. T., Li, P.P., Zhang, L.M., 2019. Protist communities are more sensitive to nitrogen fertilization than other microorganisms in diverse agricultural soils. Microbiome 7, 33. 